\title{
Seasonal and site-specific variation in vapour and aerosol phase PAHs over Flanders (Belgium) and their relation with anthropogenic activities
}

\author{
Khaiwal Ravindra ${ }^{1}$, László Bencs ${ }^{1,2}$, Eric Wauters ${ }^{3}$, Johan de Hoog ${ }^{1}$, Felix Deutsch ${ }^{4}$, \\ Edward Roekens ${ }^{5}$, Nico Bleux ${ }^{4}$, Patrick Berghmans ${ }^{4}$, and René Van Grieken ${ }^{{ }^{*}}$ \\ ${ }^{1}$ Micro and Trace Analysis Centre, Department of Chemistry, University of \\ Antwerp, Universiteitsplein 1, B-2610 Antwerp, Belgium \\ ${ }^{2}$ Research Institute for Solid State Physics and Optics of the Hungarian Academy of \\ Sciences, POB 49, H-1525 Budapest, Hungary \\ ${ }^{3}$ Flemish Environment Agency (VMM), Krijgslaan 281, S2, B-9000 Gent, Belgium \\ ${ }^{4}$ Flemish Institute for Technological Research (VITO), Boeretang 200, B-2400 Mol, \\ Belgium \\ ${ }^{5}$ Flemish Environment Agency (VMM), Kronenburgstraat 45, B-2000 Antwerp, \\ Belgium
}

\begin{abstract}
The concentrations of 16 US-EPA criteria polycyclic aromatic hydrocarbons (PAHs) were monitored during different seasons at six different cities/ locations in the northern part of Belgium. Pressurized liquid extraction was used for the fast recovery of PAHs from quartz fibre filters (QFFs) and polyurethane foams (PUFs) in less than 30 minutes with minimum solvent consumption prior to their analysis with high performance liquid chromatography. The concentrations of PAHs varied significantly at the studied sites and showed relation to different anthropogenic activities, such as vehicular emission (diesel/gasoline), incinerator, petroleum/oil burning, coke production, and wood/coal combustion. The annual average PAH concentration ranged from $17 \mathrm{ng} / \mathrm{m}^{3}$ (at a rural site) to $114 \mathrm{ng} / \mathrm{m}^{3}$ (near a petroleum harbour and industry). Most of the human carcinogenic PAHs were found to be associated with suspended particulate matter, which
\end{abstract}


forms around $\sim 55 \%$ of the total PAH levels in aerosols. Relatively higher concentrations of PAHs were detected in aerosol samples during winter compared with other seasons, whereas no clear seasonal trend was observed for the vapour phase PAHs. This fraction is likely to be more local in origin; hence, it can be used as a site-specific characteristic. The site-specific concentrations of individual PAHs were also used in diagnostic ratio evaluations and in principal component analysis to find their relation with various anthropogenic activities. These results show that the vehicular emission is a major source of PAHs in Flanders, although other anthropogenic sources, as above, have also an impact on the total PAH levels.

Keywords: PAHs; human carcinogen; pressurized liquid extraction (PLE); diagnostic ratio; principal component analysis (PCA); markers.

" Corresponding author: Tel.: +32 3820 2362; Fax: +32 3820 2376; e-mail: rene.vangrieken@ua.ac.be 


\section{Introduction}

Polycyclic aromatic hydrocarbons (PAHs) are of major health concern, mainly due to their well-known carcinogenic and mutagenic properties (Ravindra et al., 2001). PAHs and their metabolites can form DNA adducts, which can induce mutation. These adverse properties, together with the still growing presence of PAHs in the environment, make their monitoring to be a top priority task in all programs for the evaluation of both the human health risk and the environmental hazards.

As it is known, PAHs are products of incomplete combustion and pyrolysis of fossil fuels and other organic materials from natural and anthropogenic sources. In urban and industrial atmospheres, PAHs are almost entirely of anthropogenic origin (Jones et al., 1989). PAHs are present in the atmosphere both in the vapour and the condensed (aerosol) phases (Bidleman et al., 1986). Low molecular weight PAHs tend to be more concentrated in the vapour phase, while the ones with higher molecular weight are often associated with particulates. Thus, it is important to reveal the abundance, distribution and potential sources of PAHs in the ambient air both in aerosols and in the vapour phase, so that air pollution caused by PAHs to be efficiently controlled.

The main sources of PAHs in towns and cities are road traffic and certain industrial processes (Lee et al., 1995; Ravindra et al., 2001). In order to enhance the accuracy of emission source identification, principal component analysis (PCA) was used in many studies (Ho et al., 2002; Park et al., 2002; Fang et al., 2004; Dallarosa et al., 2005). Additionally, as the PAHs associated with suspended particulate matter (SPM) vary significantly as a function of their emission sources, some PAH concentration ratios have been used to indicate vehicular emission sources (Rogge et al., 1993; Venkataraman 
et al., 1994; Khalili et al., 1995). The amount and type of PAHs in urban and rural areas exhibit seasonal fluctuations with generally higher concentrations in the winter season (Cotham and Bidleman, 1995; Harrison et al., 1996; Ravindra et al., 2005).

In the present study the concentration of PAHs has been evaluated in Flanders, the northern part of Belgium, with the application of a fast analytical approach for their extraction. Samples were collected from the ambient air in both the vapour and particulate phases and the variation in PAH concentrations were assessed during different meteorological and seasonal conditions. A further purpose of the study was to identify the site-specific characteristics with relation to PAH concentrations and to apply PCA to find the possible emission sources of these compounds.

\section{Experimental}

\section{Sampling sites}

Six sampling sites were selected on the base of different anthropogenic activities in Flanders, Belgium (Fig. 1). These sites include the following locations: Wingene, Hasselt, Mechelen, Antwerp-Borgerhout, Antwerp-Petroleumkaai and Zelzate. Two sampling campaigns were performed at each site during different seasons. From each campaign, 7 to 9 samples were stochastically collected. Table 1 shows the sampling period of each sampling site and the season(s) during that period. The most important meteorological parameters, such as the wind speed (WS) and wind direction (WD), the relative humidity $(\mathrm{RH})$, the air temperature $(\mathrm{T})$ and its pressure (AP), and the precipitation rate (PPT) were also monitored and recorded during the sampling campaigns near the corresponding sampling sites. 


\section{Sampling site characteristics}

Sites selected for PAH measurements in Flanders were chosen on the basis of the local differences in the type, distribution and proximity of emission sources. Two of the sampling sites are located in urban areas, i.e., Borgerhout and Mechelen, while one of the sampling sites (Wingene) is situated in a rural area. Two other sites (Zelzate and Hasselt) are located in suburban areas. One site (Petroleumkaai) is of industrial nature, as it is situated near the petroleum harbour and several refineries of Antwerp. The Zelzate site is situated near a highway. There are considerable industrial activities nearby the sampling sites at Petroleumkaai (oil-refineries and petrochemical plants), Zelzate (steel industry) and Mechelen (dye/paint). Samples were also collected near an area of high traffic intensity (Borgerhout), i.e., 40,000-50,000 cars/day.

\section{Sampling procedure}

For the determination of PAHs, atmospheric air samples were taken at $1.5 \mathrm{~m}$ height using polyurethane foam (PUF) high-volume samplers (Model GPS-1, Andersen Instruments, Village of Cleves, OH, USA). PAHs present in the particulate and vapour phases of the ambient air were trapped on quartz fibre filters (QFFs) (Gelman, Ann Arbor, MI, USA) and PUF plugs, respectively. The instrument was calibrated using a manometer and top-loading orifice plate (Graseby Anderson, OH, USA). An airflow rate of approximately $180 \mathrm{l} / \mathrm{min}$ was used with a daily sampling time of around $24 \mathrm{~h}$. After sampling, each filter and PUF was separately wrapped in aluminium foils and stored in a

freezer at $-20{ }^{\circ} \mathrm{C}$, until they were processed to sample preparation and analysis. The sampling schedule during the monitoring period is shown in Table 1. 
SPM and $\mathrm{PM}_{2.5}$ fraction of ambient air were determined by the use of a four-stage Dekati-impactor (Tampere, Finland). This unit was operated at a height of around $1.7 \mathrm{~m}$ from the ground for the same 24-hour period as the PUF-sampler and with a flow-rate of $30 \mathrm{l} / \mathrm{min}$. Nuclepore-filters with a diameter of $25 \mathrm{~mm}$ and a pore-size of $0.2 \mu \mathrm{m}$ were placed onto each stage of the impactor. Moreover, a quartz filter of $47 \mathrm{~mm}$ diameter was also placed into the last "back-up" stage of the impactor to collect the rest aerosols, i.e., the "back-up" fraction. The filters were weighed with a microbalance, before and after sampling, and the particulate fractions were calculated according to the weightdifference. The SPM and $\mathrm{PM}_{2.5}$ were also calculated from the weights of the diverse fractions collected on the impactor-stages.

\section{Sample preparation by pressurized liquid extraction (PLE)}

The samples were extracted using Accelerated Solvent Extractor (ASE, Dionex, Titan Way, CA, USA). As a first step of this procedure, the filters and PUFs were loaded into $34 \mathrm{ml}$ and $100 \mathrm{ml}$ extraction cells, respectively. The extractions were performed using a pressure of $10 \mathrm{MPa}$ at an oven temperature of $100{ }^{\circ} \mathrm{C}$. A solvent mixture of 1:1 dichloromethane/acetone was used for extraction. The flushing volume was $60 \%$ of the volume of the extraction cell. The full cycle was repeated three times, and after extraction, the instrument was purged at $1 \mathrm{MPa}$ for $60 \mathrm{~s}$ with nitrogen. Pre-rinsed $250 \mathrm{ml}$ screw cap I- Chem Vials were used to collect the extracts. Finally, before analysis, the extracts were enriched in Turbo Vap 500 (Zymark, Hopkinton, MA, USA) concentration workstation after adding $0.6 \mathrm{ml}$ acetic acid to avoid evaporation till dryness and were redissolved in $1 \mathrm{ml}$ acetonitrile. Blanks of the filters and PUFs were also extracted using the same procedure as aforementioned. 


\section{Analysis of extracted samples by HPLC}

The extracts were analysed by a high performance liquid chromatography (HPLC) system (Waters, Milford, MA, USA) with programmed fluorescence detection (PerkinElmer LC240, Norwalk, CT, USA) and UV-detection (Waters) for acenaphtylene. Separation of the PAHs was accomplished using a Vydac 201TP (250 mm x $4.6 \mathrm{~mm}$ ) column, with a gradient elution ranging from a 50+50\% acetonitrile-water mixture to $100 \%$ acetonitrile in $20 \mathrm{~min}$. The fluorescence of PAHs was monitored with an automatic adjustment of the wavelengths for each compound according to its retention time. The excitation wavelengths ranged between 260 and $300 \mathrm{~nm}$, while the emission wavelengths lay between 380 and $465 \mathrm{~nm}$. The wavelength of the UV-detector was $325 \mathrm{~nm}$. Linear calibration graphs were obtained for all the studied PAHs in the concentration ranges of up to $80 \mathrm{ng} / \mathrm{ml}$. PAH concentrations of less than a nanogram in the air samples could be quantified. The detected and quantified PAHs were: naphthalene (Nap), acenapthylene (AcPy), acenaphthene (Acp), fluorene (Flu), anthracene (Ant), phenanthrene (PA), fluoranthene (FluT), pyrene (Pyr), benzo(a)anthracene (BaA), chrysene (Chr), benzo(b)fluoranthene $(\mathrm{BbF})$, benzo(k)fluoranthene $(\mathrm{BkF})$, benzo(a)pyrene $(\mathrm{BaP})$, dibenzo(a,h)anthracene (DahA), benzo(g,h,i)perylene (BghiP) and indeno(1,2,3c,d)pyrene (Ind). For these PAHs, the limits of quantification, calculated for the volume of air sampled, were $0.034 ; 0.040 ; 0.047 ; 0.020 ; 0.003 ; 0.007 ; 0.021 ; 0.004 ; 0.021 ; 0.016$; $0.015 ; 0.020 ; 0.017 ; 0.003 ; 0.003$ and 0.010 respectively. The calculation of quantification limits and other details can be found elsewhere (Tirez, 1995). 


\section{Quality assurance}

All analytical data were subjected to strict quality control. Blank and spiked samples were analysed with each set of samples. Spiked filter and PUF samples were determined with good precisions and recoveries. Recovery efficiencies were found between 80 and $120 \%$ by using a certified reference material of the National Institute of Standards and Technology (NIST): SRM1650a (Diesel Particulate Matter). The NIST standard PAH mixture (SRM 1647d, Schmidt, Amsterdam, The Netherlands) is used for calibration of the analytical method and spiking of the test samples. The standardized test method for PAHs was accredited by Beltest (http:/belac.fgov.be) under the number 216-T (norm EN-45001 ISO- 9002).

\section{Results and discussion}

\section{Fast extraction of PAHs with ASE}

The traditional extraction methods for solid matrices are based on Soxhlet- and ultrasonic extraction. Both of these methods are time- and labour-consuming and require large amounts of organic solvents. Therefore, new extraction methods have been developed, e.g. microwave assisted extraction (MAE), supercritical fluid extraction (SFE) and application of PLE (Dean, 1998; Bøwadt and Hawthorne, 1995; EPA, 1995; Richter et al., 1996). Several studies have shown that these methods can be equally or even more efficient than Soxhlet extraction (David and Seiber, 1996; Brumley et al., 1998; Berset et al., 1999).

Application of PLE has been shown for the recovery of PAHs from various environmental matrices such as contaminated soils (Lundstedt et al., 2004), solid waste 
(Popp et al., 1997), water samples (Doong et al., 2000), fly ash, and lignite coal (Arditsoglou et al., 2003) and for mussels (Martinez et al., 2004). Further, Godoi et al. (2004) have also shown the application of PLE for the extraction of PAHs from particulate matter collected on glass fibre filters (GFFs) followed by GC-MS analysis. However, to the best of our knowledge, there is not any study in the literature, which provides fast conditions for the recovery of PAHs from QFF and PUF samples collected from ambient air prior to HPLC analysis. In the experimental section the optimum conditions for the maximum recovery of PAHs from QFF and PUF samples are provided. The results show that application of PLE offers very fast recovery of PAHs, i.e. in 28 minutes, with minimum consumption of toxic solvents. The total amounts of the solvent used for the extraction of QFF and PUF samples were $80 \mathrm{ml}$ and $60 \mathrm{ml}$, respectively. These solvent volumes can be reduced further, either by the use of appropriate size of extraction cell or by the use of inert material such as Hydromatrix (cleaned and sieved diatomaceous earth) as a solid support to fill the empty space in extraction cell, since the amount of solvent consumption depends on the sample size.

\section{Evaluation of site-specific PAH concentrations}

The background levels of PAHs in the ambient air are reported to be $0.02-1.2$ $\mathrm{ng} / \mathrm{m}^{3}$ in rural areas and $0.15-19.3 \mathrm{ng} / \mathrm{m}^{3}$ in urban areas (Ravindra et al., 2001). Because of their low vapour pressure, PAHs in air are present at ambient temperatures either as gases or condensed-phase (liquid and/or solid) particles (i.e., SPM), or gases adsorbed on the particulate fraction. The site-specific concentrations of PAHs both in the vapour- and particulate fractions were determined at various sites in Flanders during different seasons. As can be seen in Table 2, the highest annual average concentration of PAHs was found 
at Petroleumkaai $\left(114 \mathrm{ng} / \mathrm{m}^{3}\right.$ ), followed with lower concentrations by Borgerhout (54 $\left.\mathrm{ng} / \mathrm{m}^{3}\right)$, Zelzate $\left(52 \mathrm{ng} / \mathrm{m}^{3}\right)$, Hasselt $\left(43 \mathrm{ng} / \mathrm{m}^{3}\right)$, Mechelen $\left(42 \mathrm{ng} / \mathrm{m}^{3}\right)$ and Wingene $(17$ $\mathrm{ng} / \mathrm{m}^{3}$ ). Further, the average concentration of PAHs during different sampling periods varied from $15 \mathrm{ng} / \mathrm{m}^{3}$ (Wingene) to $135 \mathrm{ng} / \mathrm{m}^{3}$ (Petroleumkaai) in the vapour fraction of samples, while in the particulate fraction the concentration varied from $1 \mathrm{ng} / \mathrm{m}^{3}$ (Mechelen) to $14 \mathrm{ng} / \mathrm{m}^{3}$ (Zelzate).

This high concentration of PAHs at Petroleumkaai seems to be related with the activities of the petroleum industry in the vicinity of this sampling site. The sampling site in Borgerhout is located in downtown Antwerp nearby a main road with heavy traffic. The daily average concentration of PAHs reported at this monitoring site shows a similar trend for the concentration of individual PAH-compounds, which observation points to a common source of PAHs, most likely the vehicular emissions. The sampling station at Zelzate (a small town, $50 \mathrm{~km}$ west of Antwerp and the same distance east of the North Sea) is primarily considered as an industrial site, nearby a main road with a moderate traffic compared to the one at the Borgerhout site. Samples collected on this site showed great variations for different sampling days. This may be an indication of the influence of fluctuating industrial, and/or vehicular emissions combined with the variation in the weather conditions. The steel industry at Zelzate is located around $700 \mathrm{~m}$ south of the sampling site and hence the contribution of its emission to the total PAH concentration can be very fluctuating, mainly depending on the wind direction and its speed. The site selected in Hasselt is relatively close to the city centre, and is located at the shore of the Albert Channel. The moderately high concentration of PAHs at this site may be associated with the freighter traffic and their 
movement at sluice gates located next to the sampling site. The sampling site in Mechelen (a historic town around $25 \mathrm{~km}$ south of Antwerp) is of suburban nature and is situated some $1.5 \mathrm{~km}$ of the city centre. The relatively high total concentration of PAHs (about the same level as in Hasselt) at this site corresponds to the combined impact of the industrial influence and the medium traffic density. The total average concentration of PAHs reported at Wingene is comparatively lower than those found at the other sites. This observation can be justified, as the sampling site is primarily a rural one with negligibly small influence of industrial activities and/or emissions by vehicles, but some nearby agricultural activity can contribute to the increased background levels of PAHs.

The average total concentration of PAHs reported in the particulate fractions were $5.5 \mathrm{ng} / \mathrm{m}^{3}$, while in the vapour fractions it was $48 \mathrm{ng} / \mathrm{m}^{3}$. Consequently, most of the PAHs appeared to be present in the gas phase (more than $80 \%$ of the total amount of PAHs). FluT (12\%), Chr (11\%), BbF (11\%), BghiP (10\%), Ind (8\%) and BaP (7\%) were found to be the most common $\mathrm{PAH}$ compounds with relatively high concentrations in the particulate fraction in Flanders, whereas PA (48\%), Flu (14\%) and FluT (10\%) form the major part of the vapour fraction. Further $\mathrm{BbF}, \mathrm{Chr}, \mathrm{BaA}$ and $\mathrm{BkF}$ showed similar percentages in all filter samples, and hence, they seem to originate from a common (type of) source at all sites. The PAH compounds with a lower molecular weight (i.e. <200 Da), such as PA, were found to be almost exclusively in the gas phase.

\section{Potential toxic fraction of PAHs in ambient air of Flanders}

The carcinogenicity classifications verified by EPA Carcinogenicity Risk Assessment Endeavor Work Group (EPA, 1994) shows that BaA, BbF, BkF, BaP, Chr, DahA and Ind are considered to be probable human carcinogens, whereas other PAHs 
such as AcPy, Ant, BghiP, FluT, fluorine, PA and Pyr are not classified as promoters of the same health risk. Based on these conclusions and our observation it was found that 55 $\%$ of total $\mathrm{PAH}$ fractions in aerosols are probable carcinogenic, whereas this fraction forms only $2 \%$ of total PAHs in the vapour phase (Table 3). Hence, it can be concluded that most of the probable human carcinogens are found to be associated with SPM in Flanders. Lighty et al. (2000) have also made similar observation for combustion aerosols. Although only $2 \%$ fraction of vapour phase PAHs is a probable human carcinogen, the health risk associated with this portion cannot be ignored as the vapour phase PAHs has 10 times higher concentration in ambient air in comparison to the levels of PAHs associated with aerosol.

\section{Influence of meteorological conditions on PAH levels}

In order to reveal the atmospheric processes responsible for the spatial and temporal distribution of air pollutants, it is mandatory to analyse the local and the regional meteorology; especially wind direction and its speed, turbulence and atmospheric stability. The likelihood of chemical reactions occurring in the atmosphere also depends on ambient weather conditions because they are influenced by short wave radiation, temperature and humidity of air. Along with chemical reactions, dispersion and dilution processes induce the concentration of different substances to vary with regard to time and space. Although the relation between meteorology and air pollution has been investigated for various pollutants, there is still very little information in the literature on the dependence of PAHs and urban aerosols (SPM and $\left.\mathrm{PM}_{2.5}\right)$ on the meteorological conditions and site-specific characteristics. Thus, an attempt is made in this section to 
establish a relationship between these parameters through a statistical treatment of the data received during the sampling campaigns.

Table 4 shows the average meteorological conditions during each campaign. The prevailing wind directions, which may transport moisture or aerosol particles from distance sources, play a major role on the daily/seasonal variation of the diverse pollutants. The levels of PAHs studied in Flanders also show significant variation with relation to wind direction, although analysis of surface wind direction alone does not adequately explain the variability in the concentration of air pollutants. Hence correlation analysis was applied between various other meteorological parameters. This analysis shows that most of the parameters bear statistically a significant correlation with each other indicating that close association does exist between them. Table 5 provides the correlation matrix for these meteorological parameters and air pollutant levels monitored at different sampling sites of Flanders. Based on Table 5, the following conclusions can be drawn-

(I) Particulate PAH levels, as well as the SPM and $\mathrm{PM}_{2.5}$, show a negative correlation with temperature. These features can be explained on the basis of mixing height, which reduces with the fall in temperature and restricts the mixing of pollutants in the atmosphere. Further, more emission can be expected during winter from various sources; (II) Aerosol and vapour phase PAHs show a negative correlation with windspeed, so do SPM and $\mathrm{PM}_{2.5}$. Higher wind speed can lead to less inversion situation and better turbulent dilution of pollutants; (III) The particulate PAHs levels develop a highly significant correlation with the total SPM and $\mathrm{PM}_{2.5}$ mass, whereas the concentration of PAHs in the vapour shows only some correlation with SPM; (IV) The concentration of 
PAHs in vapour and aerosol phases also shows some degree of relation and likely indicate towards particle/vapour partitioning, which mainly depends on the vapour pressure of PAHs, amount of fine particles available, ambient temperature, etc.

The correlation matrix for various sites was also studied individually, which demonstrates that the concentrations of PAHs in the vapour and aerosol phases develop a significant correlation at Borgerhout $(\mathrm{r}=0.49, \mathrm{p}<0.05)$, Petroleumkaai $(\mathrm{r}=-0.56$, $\mathrm{p}<0.05)$, Hasselt $(r=0.68, \mathrm{p}<0.01)$, Zelzate $(r=0.92, p<0.01)$ and Mechelen $(r=0.41$, $\mathrm{p}<0.05)$, except for Wingene. This is a rural site and probably the absence of any significant PAH emission sources in and nearby Wingene results in an insignificant correlation between vapour and aerosol phase PAH levels. At Borgenhout $(r=0.50$, $\mathrm{p}<0.05)$, and Petroleumkaai $(\mathrm{r}=0.58, \mathrm{p}<0.05)$, a significant correlation was noticed between precipitation and relative humidity, probably, because only at these sites some showers occurred during the sampling dates and periods. At Hasselt, a highly significant negative correlation was noticed between wind speed and the concentration of PAHs in both the vapour and aerosol phases. Further, at Wingene, the relative humidity shows a negative correlation $(\mathrm{r}=-0.45, \mathrm{p}<0.05)$ with the levels of PAHs in aerosol, while, at Mechelen, the relative humidity and precipitation show significant positive correlations with the levels of PAHs in the vapour phase. Based on these observations, it can be suggested that both the site-specific characteristics and meteorological parameters play an important role in the change of the PAH levels in Flanders.

\section{Seasonal variation in the concentration of PAHs}

The concentrations of PAHs during different seasons at various sampling sites in Flanders are also shown in Table 2. The total PAH concentration measured at 
Petroleumkaai was almost double during summer in contrast to winter samples, although the concentration of PAHs associated with SPM was high in winter compared to the vapour phase fraction. The average total concentrations of PAHs at Borgerhout were found to be comparable at the beginning and the end of winter. There was also no significant change noticed in the total concentration of PAHs during different seasons at Hasselt and Wingene.

Other studies conducted during different seasons in Europe often showed a higher concentration of PAHs in winter than in summer by a factor of 2 to 5 (Broddin et al., 1980; Grimmer et al., 1980; Colmsjö et al., 1986; De Raat and De Meijere, 1991). Moreover, the concentrations at urban sites were found to be 2 to 3 times greater than at rural locations. The present study shows that the concentration of PAHs associated with SPM is in good agreement with other studies, i.e., showing a higher value in winter, while this is not the case for PAHs found in the vapour fraction except for Mechelen and Zelzate. A possible reason for the high concentration of particulate PAHs during winter season seems to be related with the very low temperature during these periods, which made favourable conditions for the condensation/adsorption of these species on suspended particles present in air.

The vapour phase PAHs seems to be more local in origin and hence their levels in ambient air show no significant variation during different seasons, whereas the PAHs associated with SPM may be regional and can be transported far from the source of origin. Although some of the meteorological parameters (precipitation rate and wind speed) play an important role in controlling the concentrations of PAHs at each site, at 
the same time, the site-specific emission sources may also influence their levels in the ambient air.

\section{Source identification}

The PAH contents of urban air samples can be considered to be a composite of the emission products of various local sources combined with a contribution from outside areas. Diagnostic ratio's and principal component analysis (PCA) are the most widely used techniques to identify and characterize the emission sources. These mathematical approaches were also proven to be important tools in the present study, as follows below.

\section{Evaluation of diagnostic ratios}

The concentrations of specific PAH compounds, or a group of PAHs, have been used to indicate towards the corresponding emission sources, such as Ant, PA, FluT, Pyr, $\mathrm{BaA}$ and $\mathrm{Chr}$ for coal combustion; Ant, PA, BaP and BghiP for coke production; PA, FluT and, especially, Pyr for incinerators. Ant, PA, FluT and Pyr are indicators for combustion of wood; FluT and Pyr for oil burning; FluT, Pyr and, especially, BghiP and coronene for petrol powered vehicles; FluT, Pyr with higher ratio of $\mathrm{BbF}$ and $\mathrm{BkF}$ for diesel-fueled vehicles (Duval and Friedlander, 1981; Khalili, 1995). These markers indicate some degree of similarity and overlap between the profiles from different emission source categories.

Table 6 provides the 7 diagnostic ratios between total concentrations of PAHs at various sampling sites in Flanders. A value of $0.35-0.7$ of Ind/(Ind+BghiP) ratio has been used for diesel emissions (Kavouras et al., 2001). A corresponding value has been noticed at all sites with a maximum ratio at Hasselt and Wingene. The higher ratio $(>0.5)$ of Flu/(Flu+Pyr) has been used for diesel emission, while a lower ratio $(<0.5)$ for gasoline 
emission (Rogge et al., 1993; Mandalakis et al., 2002, Fang et al., 2004). This ratio was found to be lower than 0.5 at all sites for vapour phase PAHs, likely indicating their origin from gasoline cars, while the concentration of PAHs associated with particulate matter shows its origin from diesel emissions. Khalili et al. (1995) and Guo et al. (2003) indicated that the ratio of $\mathrm{BaP} /(\mathrm{BaP}+\mathrm{Chr})$ was 0.49 and 0.73 for diesel and gasoline engines, respectively. Our values do not correspond to these values and indicate that other pollution sources possibly interfere. A higher ratio of $\mathrm{BbP} / \mathrm{BkP}$ has been noticed at all sites, which indicates the presence of diesel emission. The BaP/BghiP ratio higher than 0.6 refers to the presence of traffic emission and contribution from other PAH sources (Pandey et al., 1999; Park et al., 2002). A similar value of this ratio was found only at Borgerhout, while the other sites in Flanders do not match to this data. Caricchia et al. (1999) reported that the Ind/BghiP ratio for gasoline engines is about 0.4, while the ratio for diesel engines approaches 1.0. Most of the values for this ratio were higher than 0.5, and this is probably in agreement with the diesel emission. Although it is clear from the study of diagnostic ratios that the diesel and gasoline emissions are significant emission sources of PAHs in Flanders, it also indicates that other pollution sources exist and contribute to the PAH levels as well. Hence, in order to enhance the accuracy of the emission source identification, the method of principal component analysis was applied as follows in the next section.

\section{Principal component analysis}

Using PCA, it is possible to simplify the interpretation of complex systems and to reduce the set of variables to few new ones, called factors. Each of these factors can be identified as either an emission source, or a chemical interaction. Many of these factors 
indicate more than one possible cause. In this study, each factor from PCA is associated with a source characterisation by its most representative PAH compound(s). Source groupings were determined by using PCA with varimax rotation and the retention of principal components having eigenvalues higher than 1 of the complete data set of PAH concentrations. Further, the principal components that showed more than $15 \%$ of total variance of the data set were used as factors. Loadings determined the most representative PAH compound in each factor and a value of higher than 0.5 was selected.

Table 7 provides the results of factor analysis of total concentrations of PAHs at all the sites studied in Flanders. The PCA results show that two of the factors explain the main part of the data variance; therefore, one element for each factor has been chosen as a tracer. The high factor loading of FluT, Pyr and especially of BghiP and coronene has been suggested for gasoline powered vehicles (Duval and Friedlander, 1981; Masclet et al., 1986; Khalili, 1995), whereas Guo et al._(2003) also include BaA, BaP, BbF, BghiP and Ind as source markers of gasoline emission. Diesel emission has high factor loading for FluT, PA, Ant and Pyr (Caricchia et al., 1999; Yang et al., 1998; Ho et al., 2002, Omar et al., 2002, Fang et al., 2004). Other studies also suggest that FluT, Pyr with higher factor loading of $\mathrm{BbF}$ and $\mathrm{BkF}$ indicated towards diesel-powered vehicles (Duval and Friedlander, 1981; Khalili, 1995). Based on these observations the factor 1 of filter samples at Borgerhout, Hasselt, Mechelen and Wingene indicate towards vehicular emission. Further, the factor loadings of Petroleumkaai and Zelzate also seems partly related with vehicular emission.

According to Daisey et al. (1986), volatile compounds such as FluT and species of high molecular weight such as Ind, probably occur together in the combustion of 
lubricating oil, which might be emitted by industrial sources. The high factor loading of AcPy, Acp, Chr, BbF and benzo(e)pyrene, indicates towards stationary emission sources (Yang et al., 1998; Kulkarni and Venkataraman, 2000). The factor 2 of filter samples seems to shows a high factor loading for wood/coal emission at Borgerhout and Hasselt, whereas in Mechelen it indicates towards incinerator/oil burning, in Petroleumkaai towards oil burning and in Wingene towards stationary emission sources.

The high level of Ant, PA, BaP, BghiP and Chr has been suggested for steel industry emissions. The PAHs compounds from coke ovens are released during coking operation as fugitive emission in steel industries. The observation of high factor loading of selected PAHs at Zelzate explains that the levels of PAHs have a relation with local activities in surrounding areas, i.e., the presence of steel industry and vehicular traffic. Further, the high factor loading of related compounds in vapour phase samples also confirm this assumption, whereas the factor 2 of filter and PUF samples also indicates towards secondary emission sources, i.e., oil burning and stationary sources.

The Factor 1 for PUF samples indicated towards diesel (Borgerhout, Mechelen), gasoline (Hasselt), petroleum and oil burning (Petroleumkaai) and vehicular emissions (Wingene and Zelzate) as primary sources in Flanders. Whilst factor 2 for PUF samples suggests gasoline (Borgenhout, Mechelen), wood/coal (Hasselt), stationary (Wingene, Zelzate) also occur as secondary sources for PAHs emission.

In general the source marker study for both vapour and particulate phase PAHs reveals that vehicular emission seems to be dominating over other sources of PAHs in Flanders. In most of the cases vapour phase PAHs represents more local source of origin and can also further specify the particular dominating sources, i.e., gasoline or diesel. 
Most of the studies, conducted to identify the potential sources of PAHs, have used total PAH levels for PCA, which likely give similar results, but it is suggested to use the application of PCA separately for both vapour and particulate phase PAHs to have more clear indication about the local and regional emission sources of these compounds. This consideration is also true for the statistical analysis of other material systems existing in more than one phase in the atmosphere.

\section{Conclusion}

Samples collected from various sites in Flanders were extracted using PLE prior to their analysis with HPLC. This method offers a very fast extraction of PAHs from the air samples with excellent recovery and minimum solvent consumption. Fast procedure for $\mathrm{PAH}$ extraction and least consumption of solvent with equal or more extraction efficiency to conventional methods offer PLE as a fruitful choice of extraction.

The concentration of PAHs at various sites in Flanders was found to related with site-specific characteristics. In general, both the Petroleumkaai and the Borgerhout sampling sites showed a relatively high level of PAHs. Additionally, the concentrations of PAHs were found to be significantly higher (approximately 10-fold) in the vapour fraction of samples than in the particulate fraction. This means a certain raise in the risk of potential exposure of human to these compounds, in addition to the health effects of PAH fractions associated with SPM and $\mathrm{PM}_{2.5}$. It is to be noted here that the vapour phase PAHs well describe the site-specific activities and hence they can be used as more reliable indicators of the local PAH emissions. FluT, Chr, BbF, BghiP, Ind and BaP were found to be the most common PAH compounds with relatively high concentrations in the 
particulate fraction, whereas PA and FluT form the major part of the vapour fraction. The emission from vehicle exhausts (diesel, gasoline) was found to be a significant contributor to the atmospheric levels of PAHs in the urban environment.

\section{Acknowledgement}

This study presents part of the results obtained in the project "Metingen van $\mathrm{PM}_{2.5}$ in Vlaanderen (2001-2003)", for which financial support by the Flemish Environment Agency (Vlaamse Milieumaatschappij) is gratefully acknowledged. One of the authors (L. Bencs) also acknowledges the support of the NATO Scientific Fellowship Program under project number of 4016/NATO/03, which allowed a 3-month-stay at the University of Antwerp. 


\section{References}

Arditsoglou, A., Terzi, E., Kalaitzoglou, M., Samara, C., 2003. A comparative study on the recovery of polycyclic aromatic hydrocarbons from fly ash and lignite coal. Environmental Science and Pollution Research 10, 354-356.

Berset, J.D., Ejem, M., Holzer, R., Lischer P., 1999. Comparison of different drying, extraction and detection techniques for the determination of priority polycyclic aromatic hydrocarbons in background contaminated soil samples. Analytica Chimica Acta 383, 263-275.

Bidleman, T.F., Billings, W.N. Foreman W.T., 1986. Vapor particle partitioning of semivolatile organic compounds - estimates from field collections. Environmental Science and Technology 20, 1038-1043.

Bøwadt, S., Hawthorne, S.B., 1995. Supercritical fluid extraction in environmental analysis. Journal of Chromatography A 703, 549-571.

Broddin, G., Cautreels, W., Van Cauwenberghe, K., 1980. On the aliphatic and polyaromatic hydrocarbon levels in urban and background aerosols from Belgium and the Netherlands. Atmospheric Environment 14, 895-910.

Brumley, W.C., Latorre, E., Kelliher, V., Marcus, A., Knowles D.E., 1998. Determination of chlordane in soil by LC/GC/ECD and LC/GC/EC NIMS with comparison of ASE, SFE, and Soxhlet extraction. Journal of Liquid Chromatography and Related Technologies. 21, 1199-1216.

Caricchia, A.M., Chiavarini, S., Pezza, M., 1999. Polycyclic aromatic hydrocarbons in the urban atmospheric particulate matter in the city of Naples (Italy). Atmospheric Environment 33, 3731-3738.

Colmsjö, A.L., Zebühr, Y.U., Östman, C.E., Wadding, A., Söderström, H., 1986. Polynuclear aromatic compounds in the ambient air of Stockholm. Chemosphere, 15, 169-182.

Cotham, W.E., Bidleman, T.F., 1995. Polycyclic aromatic hydrocarbons and polychlorinated-biphenyls in air at an urban and rural site near Lake Michigan, Environmental Science and Technology 29, 2782-2789.

Daisey, J.M., Cheney J.L., Lioy P.J., 1986. Profiles of organic particulate emissions from air pollution sources - status and needs for receptors source apportionment modelling, Journal of the Air and Pollution Control Association 36, 17-33.

Dallarosa J.B., Monego J.G, Teixeira E.C., Stefens J.L., Wiegand F., 2005. Polycyclic aromatic hydrocarbons in atmospheric particles in the metropolitan area of Porto Alegre, Brazil, Atmospheric Environment 39, 1609-1625. 
David, M.D., Seiber, J.N., 1996. Comparison of extraction techniques, including supercritical fluid, high-pressure solvent, and Soxhlet, for organophosphorus hydraulic fluids from soil. Analytical Chemistry 68, 3038-3044.

Dean, J.R. 1998. Extraction Methods For Environmental Analysis, Wiley, Chichester, Ch. 6-10, pp. 99.

De Raat, W.K., De Meijere, F.A., 1991. Polycyclic aromatic hydrocarbon (PAH) concentrations in ambient airborne particles from local traffic and distant sources; variation of the PAH profile. The Science of the Total Environment, 103, 1-17.

Doong, R., Chang, S., Sun,Y., 2000. Solid-phase microextraction for determining the distribution of sixteen US Environmental Protection Agency polycyclic aromatic hydrocarbons in water samples. Journal of Chromatography A 879, 177-188.

Duval, M.M., Friedlander, S.K., 1981. Source resolution of polycyclic aromatic hydrocarbons in Los Angeles atmosphere - application of CMB with first order decay. US EPA Report No EPA-600/2-81-161.

EPA, 1994. Peer Review and Peer Involvement at the U.S. Environmental Protection Agency, Science Policy Council, Office of the Science Advisor, Environmental Protection Agency. ID 2872. http://epa.gov/osa/spc/htm/perevmem.htm

EPA Method 3545, 1995. Accelerated Solvent Extraction, Test Methods for Evaluating Solid Waste, EPA SW-846, US GPO Washington, DC, 3rd ed., Update III, July 1995.

Fang, G.C., Wu, Y.S., Chen, M.H., Ho, T.T., Huang, S.H., Rau, J.Y., 2004. Polycyclic aromatic hydrocarbons study in Taichung, Taiwan, during 2002-2003, Atmospheric Environment 38, 3385-3391.

Grimmer, G., Naujack, K.W., Schneider, D.,1980. Changes in PAH-profiles in different areas of a city during the year, pp. 107-125. In A. Bjorseth and A. J. Dennis, Eds. Polynuclear Aromatic Hydrocarbons: Chemistry and Biological Effects. 4th International Symposium. Columbus, Ohio: Battelle Press.

Godoi, A.F.L., Ravindra, K., Godoi, R.H.M., Andrade, S.J., Santiago-Silva, M., Van Vaeck, L., Van Grieken, R., 2004. Fast chromatographic determination of polycyclic aromatic hydrocarbon in aerosol samples from sugar cane burning. Journal of Chromatography A 1027, 49-53.

Guo, H., Lee, S.C., Ho, K.F., Wang, X.M., Zou, S.C., 2003. Particle-associated polycyclic aromatic hydrocarbons in urban air of Hong Kong. Atmospheric Environment 37, 5307-5317. 
Harrison, R.M., Smith, D.J.T., Luhana, L., 1996. Source apportionment of atmospheric polycyclic aromatic hydrocarbons collected from an urban location in Birmingham, UK. Environmental Science and Technology 30, 825-832.

Ho, K.F., Lee, S.C., Chiu, G.M.Y., 2002. Characterization of selected volatile organic compounds, polycyclic aromatic hydrocarbons and carbonyl compounds at a roadside monitoring station. Atmospheric Environment 36, 57-65.

Jones, K.C., Grimmer, G., Jacob, J., Johnston, A.E., 1989. Changes in the polynuclear aromatic hydrocarbon content of wheat-grain and pasture grassland over the last century from one site in the UK. The Science of the Total Environment 78, 117-130.

Kavouras, I.G., Koutrakis, P., Tsapakis, M., Lagoudaki, E., Stephanou, E.G., Von Baer, D., Oyola, P., 2001. Source apportionment of urban particulate aliphatic and polynuclear aromatic hydrocarbons (PAHs) using multivariate methods. Environmental Science and Technology 35, 2288-2294.

Khalili, N.R., Scheff, P.A., Holsen, T.M., 1995. PAH source fingerprints for coke ovens, diesel and gasoline engines, highway tunnels, and wood combustion emissions. Atmospheric Environment 29, 533-542.

Kulkarni, P., Venkataraman, C., 2000. Atmospheric polycyclic aromatic hydrocarbons in Mumbai, India. Atmospheric Environment 34, 2785-2790.

Lee, W.J., Wang, Y.F., Lin, T.C., Chen, Y.Y., Lin, W.C., Ku, C.C., Cheng, J.T., 1995. $\mathrm{PAH}$ characteristics in the ambient air of traffic-source. The Science of The Total Environment 159, 185-200.

Lighty, J.S., Veranth, J.M., Sarofim, A.F., 2000. Combustion aerosols: Factors governing their size and composition and implications to human health. Journal of Air and Waste Management Association 50, 1565-1618.

Lundstedt, S., van Bavel, B., Haglund, P., Tysklind, M., Öberg, L. , 2000. Pressurised liquid extraction of polycyclic aromatic hydrocarbons from contaminated soils. Journal of Chromatography A 883, 151-162.

Masclet P., Mouvier, G., Nikolaou, K., 1986. Relative decay index and sources of polycyclic aromatic hydrocarbons. Atmospheric Environment 20, 439-446.

Mandalakis, M., Tsapakis, M., Tsoga, A., Stephanou, E.G., 2002. Gas-particle concentrations and distribution of aliphatic hydrocarbons, PAHs, PCBs and PCDD/Fs in the atmosphere of Athens (Greece). Atmospheric Environment 36, 4023-4035.

Martinez, E., Gros, M., Lacorte, S., Barceló, D., 2004. Simplified procedures for the analysis of polycyclic aromatic hydrocarbons in water, sediments and mussels. Journal of Chromatography A 1047, 181-188. 
Omar, N.Y.M.J., Bin Abas, M.R., Ketuly, K.A., Tahir, N.M., 2002. Concentrations of PAHs in atmospheric particles (PM-10) and roadside soil particles collected in Kuala Lumpur, Malaysia. Atmospheric Environment 36, 247-254.

Pandey, P.K., Patel, K.S., Lenicek, J., 1999. Polycyclic aromatic hydrocarbons: Need for assessment of health risks in India? -Study of an urban-industrial location in India. Environmental Monitoring and Assessment 59, 287-319.

Park, S.S., Kim, Y.J., Kang, C.H., 2002. Atmospheric polycyclic aromatic hydrocarbons in Seoul, Korea. Atmospheric Environment 36, 2917-2924.

Popp, P., Keil, P., Möder, M., Paschke, A., Thuss, U., 1997. Application of accelerated solvent extraction followed by gas chromatography, high-performance liquid chromatography and gas chromatography-mass spectrometry for the determination of polycyclic aromatic hydrocarbons, chlorinated pesticides and polychlorinated dibenzo- $p$ dioxins and dibenzofurans in solid wastes. Journal of Chromatography A 774, 203-211.

Ravindra, K., Mittal, A.K., Van Grieken, R., 2001. Health risk assessment of urban suspended particulate matter with special reference to polycyclic aromatic hydrocarbons: A review. Reviews on Environmental Health 16, 169-189.

Ravindra, K., Wauters, E., Taygi, S.K., Mor, S., Van Grieken R., 2005. Assessment of air quality after the implementation of CNG as fuel in public transport in Delhi, India. Environmental Monitoring and Assessment, in press.

Richter, B.E., Jones, B.A., Ezzell, J.L., Porter, N.L., Avdalovic, N., Pohl, C., 1996. Accelerated solvent extraction: A technique for sample preparation. Analytical Chemistry 68, 1033-1039.

Rogge, W.F., Hildemann, L.M., Mazurek, M.A., Cass, G.R., Simoneit, B.R.T., 1993. Sources of fine organic aerosol: 2. Noncatalyst and catalyst-equipped automobiles and heavy-duty diesel trucks. Environmental Science and Technology 27, 636-651.

Tirez, K., 1995. Method detection limits and validation of operating procedure. Ph.D. Thesis, Ghent University, Ghent, Belgium.

Venkataraman, C., Lyons, J.M., Friedlander, S.K., 1994. Size distributions of aromatic hydrocarbons and elemental carbon. 1. Sampling, measurement methods and source characterization. Environmental Science and Technology 28, 555-562.

Yang, H.H., Lee, W.J., Chen, S.J., Lai, S.O., 1998. PAH emission from various industrial stacks. Journal of Hazardous Materials 60, 159-174. 


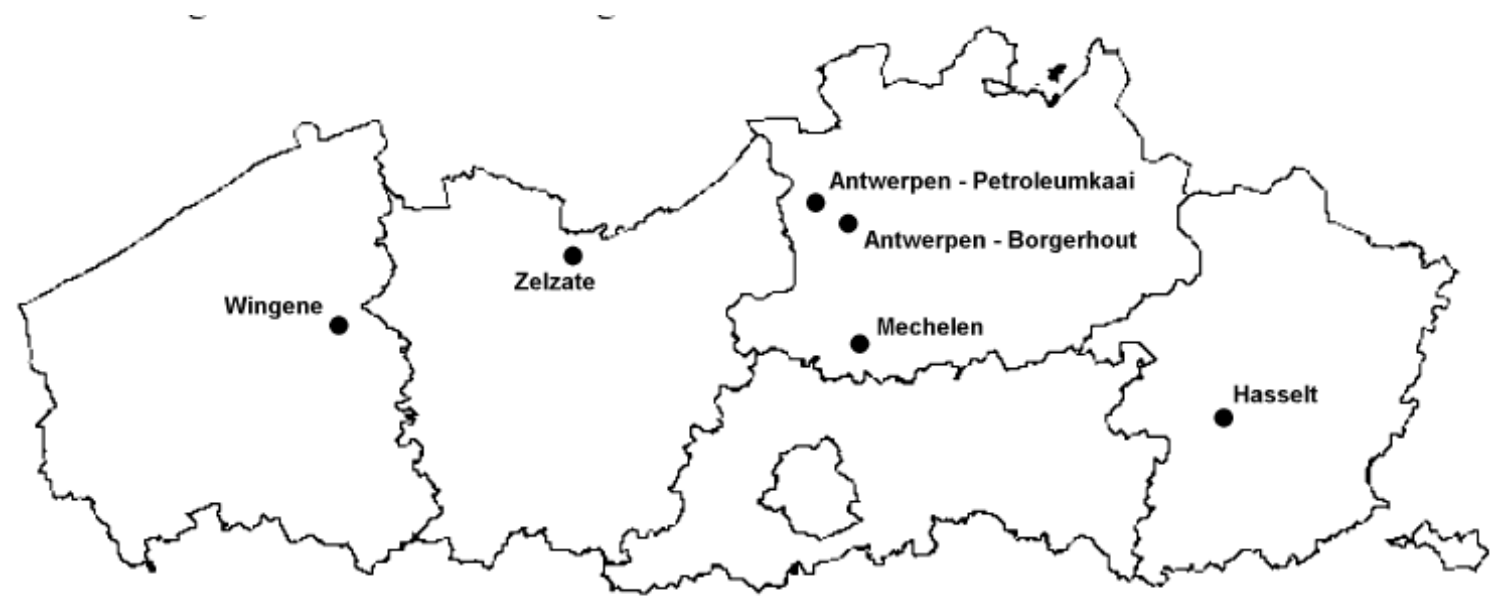

Fig. 1. Locations of various sampling sites in Flanders (Belgium)

Table 1. Sampling periods during the monitoring of PAHs

Campaign/ Location Sampling periods

\begin{tabular}{lll}
\hline Campaign 1 & Petroleumkaai (A) & $22 / 09 / 01$ to $09 / 10 / 01$ \\
& Borgerhout (A-W) & $24 / 11 / 01$ to $06 / 12 / 01$ \\
\hline Zelzate (W) & $20 / 12 / 01$ to $18 / 01 / 02$ \\
\hline Hasselt (W-Sp) & $12 / 02 / 02$ to $22 / 03 / 02$ \\
\hline Wingene (Sp) & $06 / 04 / 02$ to $14 / 05 / 02$ \\
\hline Mechelen (Sp-Su) & $24 / 05 / 02$ to $26 / 06 / 02$ \\
\hline Campaign 2 & Wingene (Su) & $27 / 06 / 02$ to $06 / 08 / 02$ \\
\hline Zelzate (Su-A) & $18 / 08 / 02$ to $11 / 09 / 02$ \\
\hline Hasselt (A) & $06 / 10 / 02$ to $04 / 11 / 02$ \\
\hline Mechelen (A-W) & $16 / 11 / 02$ to $15 / 12 / 02$ \\
\hline Petroleumkaai $(\mathrm{W})$ & $04 / 01 / 03$ to $02 / 02 / 03$ \\
\hline Borgerhout (W-Sp) & $16 / 02 / 03$ to $13 / 03 / 03$ \\
\hline
\end{tabular}

(W- winter, Sp - spring, Su- summer, A - autumn) 
Table 2. Concentration of individual PAH compounds $\left(\mathrm{ng} / \mathrm{m}^{3}\right)$ at the sampling sites in Flanders during various seasons

\begin{tabular}{|c|c|c|c|c|c|c|c|c|c|c|c|c|c|c|c|c|c|c|c|}
\hline Location/campaign & $\begin{array}{l}\text { Type } \\
\text { of } \\
\text { sample }\end{array}$ & Z & $\begin{array}{l}\text { D } \\
\text { o } \\
0 \\
<\end{array}$ & $\frac{1}{8}$ & $\frac{\pi}{\mathrm{I}}$ & $\frac{D}{D}$ & $\stackrel{D}{2}$ & $\frac{\pi}{\bar{E}}$ & $\underset{x}{0}$ & W & $\stackrel{\rho}{\rho}$ & 蕒 & $\frac{\square}{\lambda}$ & סָׁٍ & 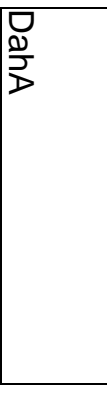 & $\frac{\text { W }}{\underline{0}}$ & $\overline{\bar{z}}$ & 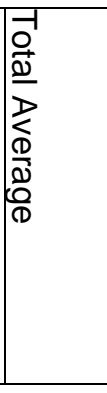 & 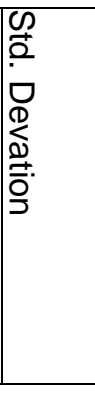 \\
\hline \multirow[t]{2}{*}{ Petroleumkaai / 1st } & Filter & 0.15 & n.d. & 0.05 & 0.02 & 0.16 & 0.01 & 0.31 & 0.08 & 0.09 & 0.17 & 0.21 & 0.10 & 0.06 & 0.16 & 0.18 & 0.17 & 1.90 & 0.94 \\
\hline & PUF & 1.65 & 0.12 & 0.09 & 19.2 & 85.0 & 4.09 & 18.4 & 5.72 & 0.09 & 0.02 & 0.11 & 0.02 & 0.02 & 0.07 & 0.26 & 0.17 & 135 & 41.8 \\
\hline \multirow[t]{2}{*}{ Petroleumkaai / 2nd } & Filter & 0.19 & 0.03 & 0.05 & 0.06 & 0.48 & 0.03 & 0.50 & 0.60 & 2.05 & 0.09 & 0.60 & 0.25 & 0.24 & 0.09 & 0.39 & 0.19 & 5.83 & 2.66 \\
\hline & PUF & 37.5 & 1.70 & 0.29 & 14.3 & 20.2 & 1.14 & 3.85 & 2.84 & 0.23 & 2.43 & 0.02 & 0.01 & 0.01 & 0.04 & 0.06 & 0.04 & 84.7 & 31.4 \\
\hline \multirow[t]{2}{*}{ Borgerhout / 1st } & Filter & 0.34 & 0.15 & 0.09 & 0.03 & 0.16 & 0.05 & 1.35 & 0.25 & 0.26 & 0.91 & 0.90 & 0.49 & 0.78 & 0.39 & 0.74 & 0.31 & 7.23 & 2.32 \\
\hline & PUF & 0.45 & 4.61 & 0.02 & 7.91 & 29.3 & 3.25 & 3.98 & 4.09 & 0.08 & 0.09 & 0.02 & 0.01 & 0.01 & 0.05 & 0.12 & 0.07 & 54.0 & 6.71 \\
\hline \multirow[t]{2}{*}{ Borgerhout / 2nd } & Filter & 0.35 & 0.08 & 0.09 & 0.06 & 0.74 & 0.09 & 1.11 & 1.15 & 0.45 & 1.39 & 1.09 & 0.49 & 0.97 & 0.42 & 1.16 & 0.53 & 10.2 & 15.8 \\
\hline & PUF & 2.73 & 2.69 & 0.01 & 6.35 & 16.6 & 1.62 & 2.96 & 3.04 & 0.28 & 1.02 & n.d. & n.d. & n.d. & 0.02 & 0.02 & 0.02 & 37.4 & 19.1 \\
\hline \multirow[t]{2}{*}{ Zelzate / 1st } & Filter & 0.62 & 0.60 & 0.47 & 0.27 & 0.55 & 0.21 & 0.75 & 0.51 & 0.65 & 1.87 & 1.73 & 0.90 & 1.27 & 0.55 & 1.39 & 1.76 & 14.1 & 10.7 \\
\hline & PUF & 2.34 & 13.6 & 0.38 & 9.54 & 29.5 & 2.10 & 6.33 & 2.15 & 0.32 & 0.44 & 0.31 & 0.11 & 0.20 & 0.35 & 0.38 & 0.32 & 68.2 & 29.5 \\
\hline \multirow[t]{2}{*}{ Zelzate / 2nd } & Filter & 0.06 & n.d. & 0.01 & 0.01 & 0.11 & n.d. & 0.14 & 0.04 & 0.02 & 0.08 & 0.10 & 0.04 & 0.01 & 0.03 & 0.08 & 0.05 & 0.76 & 0.37 \\
\hline & PUF & 0.34 & 0.07 & 0.03 & 1.90 & 13.2 & 0.35 & 3.06 & 0.97 & 0.15 & 0.09 & 0.01 & n.d. & 0.01 & 0.11 & 0.11 & 0.06 & 20.5 & 3.72 \\
\hline \multirow[t]{2}{*}{ Hasselt / 1st } & Filter & 0.32 & 0.01 & 0.05 & 0.02 & 0.24 & 0.02 & 0.41 & 0.14 & 0.23 & 0.45 & 0.61 & 0.27 & 0.26 & 0.13 & 0.53 & 0.98 & 4.67 & 3.73 \\
\hline & PUF & 3.52 & 1.41 & 0.20 & 5.13 & 20.4 & 0.64 & 3.02 & 1.36 & 0.10 & 0.09 & 0.03 & 0.02 & 0.03 & 0.42 & 0.39 & 0.45 & 37.2 & 13.4 \\
\hline \multirow[t]{2}{*}{ Hasselt / 2nd } & Filter & 0.06 & n.d. & 0.02 & 0.01 & 0.47 & 0.01 & 0.96 & 0.40 & 0.11 & 0.40 & 0.55 & 0.22 & 0.06 & 0.07 & 0.48 & 0.55 & 4.37 & 3.53 \\
\hline & PUF & 1.26 & 1.12 & 0.01 & 3.05 & 28.0 & 0.57 & 3.29 & 1.68 & n.d. & 0.12 & n.d. & n.d. & n.d. & 0.01 & 0.01 & 0.01 & 39.1 & 15.3 \\
\hline \multirow[t]{2}{*}{ Wingene / 1st } & Filter & 0.22 & 0.01 & 0.06 & 0.02 & 0.05 & 0.01 & 0.10 & 0.07 & 0.08 & 0.09 & 0.17 & 0.06 & 0.05 & 0.05 & 0.06 & 0.09 & 1.18 & 0.68 \\
\hline & PUF & 3.55 & 0.42 & 0.08 & 1.64 & 6.76 & 0.15 & 1.04 & 0.41 & 0.05 & 0.03 & 0.02 & 0.01 & 0.02 & 0.16 & 0.11 & 0.16 & 14.6 & 5.28 \\
\hline \multirow[t]{2}{*}{ Wingene / 2nd } & Filter & 0.06 & 0.01 & 0.02 & 0.04 & 0.25 & n.d. & 0.09 & 0.03 & 0.01 & 0.02 & 0.05 & 0.02 & n.d. & 0.02 & 0.05 & 0.03 & 0.70 & 0.73 \\
\hline & PUF & 8.58 & 0.09 & 0.29 & 0.68 & 3.56 & 0.07 & 2.81 & 0.25 & 0.02 & 0.17 & n.d. & n.d. & n.d. & 0.01 & 0.02 & 0.01 & 16.5 & 9.62 \\
\hline \multirow[t]{2}{*}{ Mechelen / 1st } & Filter & 0.05 & 0.02 & 0.01 & 0.03 & 0.10 & n.d. & 0.16 & 0.03 & 0.05 & 0.08 & 0.12 & 0.03 & 0.01 & 0.04 & 0.08 & 0.06 & 0.84 & 0.37 \\
\hline & PUF & 10.8 & 0.40 & 5.09 & 1.24 & 4.41 & n.d. & 1.40 & 0.30 & 0.25 & 0.36 & 0.02 & 0.01 & 0.01 & 0.02 & 0.05 & 0.03 & 24.4 & 18.6 \\
\hline \multirow[t]{2}{*}{ Mechelen / 2nd } & Filter & 0.44 & 0.02 & 0.05 & 0.09 & 0.95 & 0.10 & 1.94 & 1.94 & 0.78 & 1.53 & 1.58 & 0.72 & 1.06 & 0.53 & 1.48 & 0.71 & 13.9 & 12.9 \\
\hline & PUF & 4.01 & 4.06 & 0.01 & 6.81 & 17.7 & 1.63 & 4.25 & 2.99 & 0.45 & 1.73 & 0.02 & n.d. & 0.01 & 0.03 & 0.05 & 0.04 & 43.8 & 11.5 \\
\hline
\end{tabular}

n.d. - not detected 
Table 3: Potential toxic fraction of total PAHs concentration at various sites in Flanders.

\begin{tabular}{|l|l|c|c|}
\hline Sampling site & Phase & $\begin{array}{c}\text { Average PAH concentration } \\
\left(\mathrm{ng} / \mathrm{m}^{3}\right)\end{array}$ & Toxic fraction* (\%) \\
\hline \multirow{2}{*}{ Petroleumkaai } & Aerosol & 3.9 & 57.5 \\
\cline { 2 - 4 } & Vapour & 110 & 1.5 \\
\hline \multirow{2}{*}{ Borgerhout } & Aerosol & 8.7 & 54.1 \\
\cline { 2 - 4 } & Vapour & 45.7 & 1.8 \\
\hline \multirow{2}{*}{ Helzate } & Aerosol & 7.4 & 61 \\
\cline { 2 - 4 } & Vapour & 44.4 & 2.7 \\
\hline \multirow{2}{*}{ Wingene } & Aerosol & 4.5 & 54.1 \\
\cline { 2 - 4 } & Vapour & 38.2 & 1.6 \\
\hline \multirow{2}{*}{ Mechelen } & Aerosol & 0.9 & 39.3 \\
\cline { 2 - 4 } & Vapour & 15.6 & 2.1 \\
\cline { 2 - 4 } & Vapour & 7.4 & 49.4 \\
\hline
\end{tabular}

* the percent of total PAH concentration

Table 4. Meteorological parameters recorded during each campaign

\begin{tabular}{|c|c|c|c|c|c|c|c|c|c|c|c|c|}
\hline \multirow{2}{*}{$\begin{array}{l}\text { Meteorological } \\
\text { parameters }\end{array}$} & \multicolumn{2}{|c|}{ Petroleumkaai } & \multicolumn{2}{|c|}{ Borgerhout } & \multicolumn{2}{|c|}{ Zelzate } & \multicolumn{2}{|c|}{ Hasselt } & \multicolumn{2}{|c|}{ Wingene } & \multicolumn{2}{|c|}{ Mechelen } \\
\hline & $1^{\mathrm{st}}$ & $2^{\text {nd }}$ & $1^{\text {st }}$ & $2^{\text {nd }}$ & $1^{\mathrm{st}}$ & $2^{\text {nd }}$ & $1^{\mathrm{st}}$ & $2^{\text {nd }}$ & $1^{\mathrm{st}}$ & $2^{\text {nd }}$ & $1^{\mathrm{st}}$ & $2^{\text {nd }}$ \\
\hline Temperature $\left({ }^{\circ} \mathrm{C}\right)$ & $15.1 \pm 1.6$ & $4.7 \pm 3.4$ & $8.9 \pm 2.2$ & $7.1 \pm 3.6$ & $2.1 \pm 2.7$ & $17.7 \pm 2.4$ & $9.7 \pm 2.4$ & $11.1 \pm 1.9$ & $10.3 \pm 2.8$ & $17.4 \pm 3.4$ & $16.8 \pm 3.1$ & $6.2 \pm 3.8$ \\
\hline Air Pressure $(\mathrm{hPa})$ & $1011 \pm 5$ & $1014 \pm 13$ & - & $1022 \pm 8$ & - & $1017 \pm 5$ & - & $1010 \pm 8$ & $1018 \pm 8$ & $1013 \pm 5$ & $1012 \pm 7$ & $1012 \pm 10$ \\
\hline Precipitation (mm) & $0.1 \pm 0.1$ & $0.0 \pm 0.0$ & $0.1 \pm 0.1$ & $0.0 \pm 0.0$ & $0.1 \pm 0.1$ & $0.0 \pm 0.0$ & $0.1 \pm 0.1$ & $0.1 \pm 0.1$ & $0.0 \pm 0.0$ & $0.1 \pm 0.1$ & $0.1 \pm 0.1$ & $0.0 \pm 0.0$ \\
\hline Relative Humidity (\%) & $71 \pm 5$ & $73 \pm 5$ & $78 \pm 5$ & $66 \pm 9$ & $90 \pm 6$ & $84 \pm 7$ & $68 \pm 8$ & $70 \pm 6$ & $74 \pm 10$ & $78 \pm 8$ & $61 \pm 6$ & $75 \pm 7$ \\
\hline Wind Speed $(\mathrm{m} / \mathrm{s})$ & $4.1 \pm 1.7$ & $4.9 \pm 1.4$ & $4.0 \pm 1.5$ & $3.8 \pm 1.3$ & $4.8 \pm 2$ & $3.5 \pm 1.2$ & $5.0 \pm 1.6$ & $4.5 \pm 1.8$ & $3.9 \pm 1.0$ & $3.7 \pm 1.3$ & $3.9 \pm 1.0$ & $3.6 \pm 1.4$ \\
\hline Wind Direction $^{1}$ & SW & SW & SW & NE/ES & SW & $\mathrm{N} / \mathrm{NE}$ & SW & SW & SW & SW & SW & EW/SW \\
\hline
\end{tabular}

The data represent average values with standard deviation $( \pm \mathrm{SD})$; exception is the wind direction for which the prevailing ones are indicated. 
Table 5: Correlation matrix of various air pollutants and meteorological parameters.

\begin{tabular}{|c|c|c|c|c|c|c|c|c|c|}
\hline & $\mathrm{RH}$ & PPT & $\mathrm{T}$ & $\mathrm{AP}$ & WS & A-PAH & V-PAH & $\mathrm{PM}_{2.5}$ & SPM \\
\hline $\mathrm{RH}$ & 1.00 & 0.15 & -0.10 & -0.04 & $-0.29 * *$ & 0.03 & 0.02 & -0.14 & -.11 \\
\hline PPT & & 1.00 & 0.03 & $-0.22 *$ & 0.08 & -0.10 & 0.09 & 0.10 & 0.04 \\
\hline $\mathrm{T}$ & & & 1.00 & -0.11 & -0.13 & $-0.66 * *$ & -0.16 & $-0.41 *$ & $-0.43 * *$ \\
\hline AP & & & & 1.00 & $-0.21 *$ & 0.14 & -0.19 & 0.17 & 0.18 \\
\hline WS & & & & & 1.00 & -0.13 & -0.10 & $-.23^{*}$ & $-0.23^{*}$ \\
\hline A-PAH & & & & & & 1.00 & $0.20 *$ & $0.62 * *$ & $0.63 * *$ \\
\hline V-PAH & & & & & & & 1.00 & 0.19 & $0.23 *$ \\
\hline $\mathrm{PM}_{2.5}$ & & & & & & & & 1.00 & $0.98 * *$ \\
\hline SPM & & & & & & & & & 1.00 \\
\hline
\end{tabular}

Abbreviations: A-PAH - Aerosol phase PAH level; V-PAH - Vapour phase PAH level; $\mathrm{RH}$ - relative humidity; PPT - precipitation rate; $\mathrm{T}$ - temperature; AP - air pressure; WS - wind-speed; 
Table 6. Diagnostic ratios of PAHs at various sites in Flanders.

\begin{tabular}{|c|c|c|c|c|c|c|c|c|}
\hline Location/campaign & $\begin{array}{l}\text { Type of } \\
\text { sample }\end{array}$ & 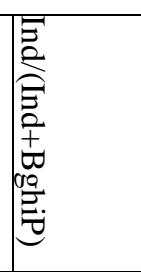 & 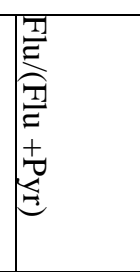 & 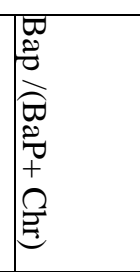 & $\mid \begin{array}{l}\vec{D} \\
\vec{\nabla} \\
\vec{D} \\
+ \\
D \\
D\end{array}$ & 离 & 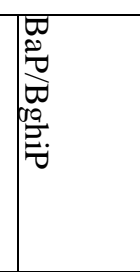 & 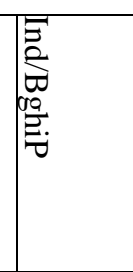 \\
\hline \multirow[t]{3}{*}{ Petroleumkaai/1st } & Filter & 0.49 & 0.18 & 0.26 & 0.92 & 2.16 & 0.35 & 0.94 \\
\hline & PUF & 0.40 & 0.77 & 0.48 & 0.95 & 5.44 & 0.07 & 0.66 \\
\hline & Total & 0.44 & 0.77 & 0.29 & 0.95 & 2.72 & 0.18 & 0.77 \\
\hline \multirow[t]{3}{*}{ Petroleumkaai/2nd } & Filter & 0.33 & 0.09 & 0.72 & 0.95 & 2.46 & 0.60 & 0.48 \\
\hline & PUF & 0.44 & 0.83 & 0.00 & 0.95 & 2.80 & 0.12 & 0.79 \\
\hline & Total & 0.34 & 0.81 & 0.09 & 0.95 & 2.47 & 0.54 & 0.52 \\
\hline \multirow[t]{3}{*}{ Borgerhout/ 1st } & Filter & 0.30 & 0.09 & 0.46 & 0.78 & 1.83 & 1.05 & 0.42 \\
\hline & PUF & 0.38 & 0.66 & 0.10 & 0.90 & 1.71 & 0.09 & 0.62 \\
\hline & Total & 0.31 & 0.65 & 0.44 & 0.90 & 1.83 & 0.92 & 0.45 \\
\hline \multirow[t]{3}{*}{ Borgerhout/2nd } & Filter & 0.31 & 0.05 & 0.41 & 0.89 & 2.22 & 0.84 & 0.46 \\
\hline & PUF & 0.48 & 0.68 & 0.00 & 0.91 & 0.00 & 0.08 & 0.92 \\
\hline & Total & 0.32 & 0.61 & 0.29 & 0.91 & 2.23 & 0.82 & 0.46 \\
\hline \multirow{3}{*}{ Zelzate/ 1st } & Filter & 0.56 & 0.35 & 0.40 & 0.72 & 1.91 & 0.91 & 1.27 \\
\hline & PUF & 0.45 & 0.82 & 0.31 & 0.93 & 2.73 & 0.53 & 0.83 \\
\hline & Total & 0.54 & 0.79 & 0.39 & 0.93 & 2.00 & 0.83 & 1.17 \\
\hline \multirow[t]{3}{*}{ Zelzate/2nd } & Filter & 0.41 & 0.20 & 0.09 & 1.00 & 2.83 & 0.10 & 0.69 \\
\hline & PUF & 0.36 & 0.66 & 0.08 & 0.97 & 7.00 & 0.07 & 0.55 \\
\hline & Total & 0.38 & 0.65 & 0.08 & 0.97 & 2.97 & 0.08 & 0.61 \\
\hline \multirow[t]{3}{*}{ Hasselt/ 1st } & Filter & 0.65 & 0.10 & 0.37 & 0.91 & 2.29 & 0.50 & 1.84 \\
\hline & PUF & 0.54 & 0.79 & 0.22 & 0.97 & 1.29 & 0.06 & 1.17 \\
\hline & Total & 0.61 & 0.77 & 0.35 & 0.97 & 2.21 & 0.31 & 1.56 \\
\hline \multirow[t]{3}{*}{ Hasselt/ 2nd } & Filter & 0.53 & 0.02 & 0.14 & 0.99 & 2.48 & 0.13 & 1.14 \\
\hline & PUF & 0.41 & 0.64 & 0.00 & 0.98 & 0.00 & 0.00 & 0.70 \\
\hline & Total & 0.53 & 0.59 & 0.11 & 0.98 & 2.46 & 0.13 & 1.12 \\
\hline \multirow[t]{3}{*}{ Wingene/ 1st } & Filter & 0.61 & 0.18 & 0.37 & 0.84 & 2.82 & 0.89 & 1.55 \\
\hline & PUF & 0.60 & 0.80 & 0.31 & 0.98 & 1.83 & 0.14 & 1.47 \\
\hline & Total & 0.60 & 0.78 & 0.35 & 0.98 & 2.65 & 0.40 & 1.50 \\
\hline \multirow[t]{3}{*}{ Wingene/ 2nd } & Filter & 0.42 & 0.54 & 0.11 & 0.98 & 2.75 & 0.06 & 0.72 \\
\hline & PUF & 0.32 & 0.73 & 0.01 & 0.98 & --- & 0.07 & 0.47 \\
\hline & Total & 0.39 & 0.71 & 0.02 & 0.98 & 3.00 & 0.06 & 0.64 \\
\hline \multirow[t]{3}{*}{ Mechelen/ 1st } & Filter & 0.43 & 0.45 & 0.11 & 1.00 & 4.04 & 0.13 & 0.76 \\
\hline & PUF & 0.37 & 0.80 & 0.03 & 1.00 & 1.80 & 0.20 & 0.59 \\
\hline & Total & 0.41 & 0.79 & 0.04 & 1.00 & 3.46 & 0.16 & 0.69 \\
\hline \multirow[t]{3}{*}{ Mechelen/2nd } & Filter & 0.32 & 0.04 & 0.41 & 0.91 & 2.21 & 0.72 & 0.48 \\
\hline & PUF & 0.43 & 0.69 & 0.00 & 0.92 & 4.00 & 0.15 & 0.75 \\
\hline & Total & 0.33 & 0.58 & 0.25 & 0.92 & 2.22 & 0.70 & 0.49 \\
\hline
\end{tabular}


Table 7a. Factor analysis of total PAH concentration data set of various sampling sites.

\begin{tabular}{|c|c|c|c|c|c|c|c|c|c|c|c|c|}
\hline & \multicolumn{6}{|c|}{ Borgerhout } & \multicolumn{6}{|c|}{ Hasselt } \\
\hline & Filter & & PUF & & Total & & Filter & & PUF & & Total & \\
\hline & Factor 1 & Factor 2 & Factor 1 & Factor 2 & Factor 1 & Factor 2 & Factor 1 & Factor 2 & Factor 1 & Factor 2 & Factor 1 & Factor 2 \\
\hline Nap & 0.49 & -0.45 & 0.41 & -0.72 & -0.74 & 0.41 & 0.10 & 0.88 & 0.56 & 0.30 & 0.53 & 0.34 \\
\hline Acpy & 0.41 & 0.56 & 0.79 & -0.26 & -0.84 & 0.38 & 0.85 & 0.45 & 0.15 & 0.76 & 0.79 & 0.41 \\
\hline Acp & 0.05 & -0.35 & -0.63 & 0.08 & 0.63 & -0.28 & -0.13 & 0.51 & 0.48 & -0.35 & 0.09 & 0.14 \\
\hline Flu & -0.14 & 0.81 & 0.85 & -0.31 & -0.91 & 0.31 & -0.43 & 0.64 & 0.54 & 0.61 & 0.82 & 0.40 \\
\hline PA & 0.70 & 0.59 & 0.97 & -0.13 & -0.87 & 0.42 & 0.83 & -0.42 & -0.38 & 0.83 & 0.88 & 0.18 \\
\hline Ant & 0.78 & 0.60 & 0.93 & -0.15 & -0.84 & 0.45 & 0.56 & 0.68 & 0.04 & 0.91 & 0.79 & 0.46 \\
\hline FluT & 0.59 & -0.47 & 0.77 & -0.61 & -0.64 & 0.69 & 0.86 & -0.47 & -0.16 & 0.88 & 0.72 & 0.44 \\
\hline Pyr & 0.85 & 0.47 & 0.88 & -0.38 & -0.69 & 0.68 & 0.92 & -0.38 & -0.25 & 0.92 & 0.78 & 0.39 \\
\hline $\mathrm{BaA}$ & 0.95 & -0.14 & 0.32 & -0.79 & 0.45 & 0.82 & 0.85 & 0.50 & 0.47 & -0.07 & -0.47 & 0.55 \\
\hline Chr & 0.94 & -0.21 & -0.82 & -0.22 & 0.58 & 0.34 & 1.00 & -0.02 & -0.29 & 0.50 & -0.70 & 0.47 \\
\hline $\mathrm{BbF}$ & 0.97 & -0.21 & 0.42 & 0.69 & 0.88 & 0.43 & 0.97 & -0.17 & 0.84 & 0.19 & -0.81 & 0.40 \\
\hline $\mathrm{BkF}$ & 0.93 & -0.30 & 0.60 & 0.72 & 0.88 & 0.41 & 0.99 & 0.01 & 0.75 & 0.01 & -0.86 & 0.40 \\
\hline $\mathrm{BaP}$ & 0.97 & -0.12 & 0.31 & 0.71 & 0.86 & 0.47 & 0.37 & 0.88 & 0.95 & 0.00 & -0.57 & 0.33 \\
\hline DahA & 0.59 & -0.15 & 0.69 & 0.55 & 0.78 & 0.30 & 0.98 & -0.01 & 0.77 & 0.35 & 0.34 & 0.70 \\
\hline BghiP & 0.92 & 0.15 & 0.33 & 0.82 & 0.84 & 0.45 & 0.97 & 0.13 & 0.73 & -0.11 & -0.63 & 0.63 \\
\hline Ind & 0.98 & -0.02 & 0.46 & 0.82 & 0.84 & 0.49 & 0.99 & -0.11 & 0.88 & 0.05 & -0.75 & 0.71 \\
\hline EigenValue & 9.32 & 2.70 & 7.30 & 5.07 & 9.65 & 3.71 & 10.17 & 3.73 & 5.46 & 4.72 & 7.37 & 3.38 \\
\hline Variance $(\%)$ & 58.24 & 16.86 & 45.64 & 31.67 & 60.33 & 23.16 & 63.54 & 23.30 & 34.15 & 29.47 & 46.08 & 21.15 \\
\hline Cumulative (\%) & 58.24 & 75.10 & 45.67 & 77.30 & 60.33 & 83.49 & 63.54 & 86.84 & 34.15 & 63.62 & 46.08 & 67.23 \\
\hline Origin & Vehicular & Wood & Diesel & Gasoline & Vehicular & Wood/Coal & Vehicular & Coal/? & Gasoline & Wood/Coal & Diesel & Gasoline \\
\hline
\end{tabular}


Table 7b. Factor analysis of total PAH concentration data set of various sampling sites.

\begin{tabular}{|c|c|c|c|c|c|c|c|c|c|c|c|c|}
\hline \multirow[b]{4}{*}{ Nan } & \multicolumn{6}{|c|}{ Mechelen } & \multicolumn{6}{|c|}{ Petroleumkaai } \\
\hline & \multirow{3}{*}{$\begin{array}{c}\text { Filter } \\
\text { Factor } 1 \\
0.56\end{array}$} & \multirow{3}{*}{$\begin{array}{c}\text { Factor } 2 \\
0.30\end{array}$} & \multirow{3}{*}{$\begin{array}{c}\text { PUF } \\
\text { Factor } 1 \\
-0.85\end{array}$} & \multirow{3}{*}{$\begin{array}{c}\text { Factor } 2 \\
0.38\end{array}$} & \multirow{3}{*}{$\begin{array}{c}\text { Total } \\
\text { Factor } 1 \\
-0.44\end{array}$} & \multirow{3}{*}{$\begin{array}{c}\text { Factor } 2 \\
-0.22\end{array}$} & \multirow{3}{*}{$\begin{array}{c}\text { Filter } \\
\text { Factor } 1 \\
-0.41\end{array}$} & \multirow{3}{*}{$\begin{array}{c}\text { Factor } 2 \\
-0.71\end{array}$} & \multirow{3}{*}{$\begin{array}{c}\text { PUF } \\
\text { Factor } 1 \\
-0.68\end{array}$} & \multirow{3}{*}{$\begin{array}{c}\text { Factor } 2 \\
-0.53\end{array}$} & \multirow{3}{*}{$\begin{array}{c}\text { Total } \\
\text { Factor } 1 \\
0.36\end{array}$} & \multirow{3}{*}{$\begin{array}{c}\text { Factor } 2 \\
-0.57\end{array}$} \\
\hline & & & & & & & & & & & & \\
\hline & & & & & & & & & & & & \\
\hline Acpy & 0.15 & 0.76 & 0.42 & -0.02 & -0.66 & 0.52 & 0.29 & -0.49 & -0.30 & 0.87 & 0.57 & -0.20 \\
\hline Acp & 0.48 & -0.35 & -0.80 & 0.36 & -0.13 & -0.43 & 0.12 & 0.40 & -0.57 & 0.27 & 0.50 & -0.49 \\
\hline Flu & 0.54 & 0.61 & 0.88 & 0.37 & -0.72 & 0.67 & -0.35 & 0.87 & 0.32 & 0.84 & 0.88 & 0.21 \\
\hline PA & -0.38 & 0.83 & 0.96 & 0.27 & -0.64 & 0.75 & -0.21 & 0.80 & 0.96 & -0.11 & 0.64 & 0.73 \\
\hline Ant & 0.04 & 0.91 & 0.85 & 0.35 & -0.63 & 0.72 & 0.60 & 0.25 & 0.94 & 0.04 & 0.72 & 0.67 \\
\hline FluT & -0.16 & 0.88 & 0.92 & 0.30 & 0.04 & 0.94 & 0.55 & -0.53 & 0.97 & 0.20 & 0.68 & 0.71 \\
\hline Pyr & -0.25 & 0.92 & 0.97 & -0.03 & 0.29 & 0.91 & 0.88 & 0.45 & 0.74 & 0.42 & 0.74 & 0.48 \\
\hline $\mathrm{BaA}$ & 0.47 & -0.07 & 0.88 & 0.36 & 0.72 & 0.55 & 0.85 & 0.49 & -0.07 & 0.39 & -0.92 & 0.05 \\
\hline $\mathrm{Chr}$ & -0.29 & 0.50 & 0.69 & -0.59 & 0.46 & 0.76 & -0.10 & 0.97 & -0.88 & 0.41 & 0.67 & -0.49 \\
\hline $\mathrm{BbF}$ & 0.84 & 0.19 & -0.19 & -0.04 & 0.99 & 0.08 & 0.98 & 0.09 & 0.60 & -0.02 & -0.94 & 0.13 \\
\hline $\mathrm{BkF}$ & 0.75 & 0.01 & -0.13 & -0.10 & 0.99 & 0.08 & 0.98 & 0.03 & 0.83 & -0.45 & -0.93 & 0.16 \\
\hline $\mathrm{BaP}$ & 0.95 & 0.00 & -0.43 & -0.65 & 0.97 & 0.06 & 0.96 & 0.07 & 0.62 & 0.61 & -0.92 & 0.15 \\
\hline DahA & 0.77 & 0.35 & -0.23 & 0.38 & 0.85 & 0.33 & 0.73 & -0.51 & -0.11 & 0.79 & -0.58 & 0.05 \\
\hline BghiP & 0.73 & -0.11 & -0.32 & 0.80 & 0.98 & 0.07 & 0.87 & -0.13 & 0.82 & 0.02 & -0.74 & 0.37 \\
\hline Ind & 0.88 & 0.05 & -0.71 & 0.53 & 0.97 & -0.01 & 0.95 & 0.01 & 0.52 & -0.34 & -0.58 & 0.58 \\
\hline EigenValue & 12.52 & 1.54 & 7.89 & 2.64 & 8.30 & 4.75 & 7.63 & 4.31 & 7.45 & 3.67 & 8.53 & 3.17 \\
\hline Variance $(\%)$ & 78.23 & 9.64 & 49.33 & 16.78 & 51.94 & 29.68 & 47.70 & 26.97 & 46.56 & 22.96 & 53.30 & 19.80 \\
\hline Cumulative (\%) & 78.23 & 87.87 & 49.33 & 66.10 & 51.94 & 81.61 & 47.70 & 74.67 & 46.56 & 69.52 & 53.30 & 73.10 \\
\hline Origin & Vehicular & $\begin{array}{c}\text { Incinerator } \\
\text { /oil }\end{array}$ & Diesel & Gasoline & Vehicular & $\begin{array}{c}\text { Incinerator } \\
\text { /oil }\end{array}$ & $\begin{array}{l}\text { Petroleum/ } \\
\text { Vehicular }\end{array}$ & $\begin{array}{c}\text { Oil } \\
\text { burning }\end{array}$ & $\begin{array}{l}\text { Petroleum/ } \\
\text { oil burning }\end{array}$ & $?$ & $\begin{array}{l}\text { Petroleum } \\
\text { Industry }\end{array}$ & Diesel \\
\hline
\end{tabular}


Table 7c. Factor analysis of total PAH concentration data set of various sampling sites.

\begin{tabular}{|c|c|c|c|c|c|c|c|c|c|c|c|c|}
\hline & \multicolumn{6}{|c|}{ Wingene } & \multicolumn{6}{|c|}{ Zelzate } \\
\hline & Filter & & PUF & & Total & & Filter & & PUF & & Total & \\
\hline & Factor 1 & Factor 2 & Factor 1 & Factor 2 & Factor 1 & Factor 2 & Factor 1 & Factor 2 & Factor 1 & Factor 2 & Factor 1 & Factor 2 \\
\hline Nap & -0.68 & -0.53 & -0.43 & 0.81 & -0.11 & 0.63 & 0.53 & 0.77 & 0.81 & -0.54 & 0.28 & 0.82 \\
\hline Acpy & -0.30 & 0.87 & 0.70 & 0.40 & 0.76 & 0.16 & 0.83 & 0.44 & 0.93 & -0.27 & 0.22 & 0.93 \\
\hline Acp & -0.57 & 0.27 & -0.29 & 0.60 & -0.12 & 0.45 & 0.79 & 0.45 & 0.83 & -0.23 & 0.60 & 0.62 \\
\hline Flu & 0.32 & 0.84 & 0.82 & -0.16 & 0.86 & 0.20 & 0.64 & 0.67 & 0.94 & -0.21 & 0.16 & 0.95 \\
\hline PA & 0.96 & -0.11 & 0.79 & -0.33 & 0.85 & 0.25 & 0.79 & -0.57 & 0.95 & 0.03 & 0.05 & 0.91 \\
\hline Ant & 0.94 & 0.04 & 0.70 & -0.22 & 0.80 & 0.32 & 0.95 & -0.24 & 0.98 & -0.14 & 0.26 & 0.95 \\
\hline FluT & 0.97 & 0.20 & -0.30 & -0.84 & 0.10 & 0.45 & 0.92 & -0.37 & 0.23 & 0.49 & 0.06 & 0.35 \\
\hline Pyr & 0.74 & 0.42 & 0.74 & -0.26 & 0.83 & 0.27 & 0.96 & 0.06 & 0.56 & 0.29 & 0.24 & 0.71 \\
\hline $\mathrm{BaA}$ & -0.07 & 0.39 & 0.57 & 0.05 & 0.59 & -0.03 & 0.98 & -0.12 & 0.62 & -0.57 & 0.94 & 0.00 \\
\hline Chr & -0.88 & 0.41 & -0.47 & 0.75 & -0.24 & 0.51 & 0.97 & -0.18 & 0.56 & 0.77 & 0.94 & -0.30 \\
\hline $\mathrm{BbF}$ & 0.60 & -0.02 & 0.81 & 0.17 & 0.14 & -0.82 & 0.93 & -0.29 & 0.85 & -0.37 & 0.91 & -0.25 \\
\hline $\mathrm{BkF}$ & 0.83 & -0.45 & 0.81 & 0.26 & 0.11 & -0.86 & 0.97 & -0.05 & 0.94 & -0.10 & 0.93 & -0.29 \\
\hline $\mathrm{BaP}$ & 0.62 & 0.61 & 0.96 & 0.12 & 0.91 & -0.23 & 0.96 & -0.26 & 0.71 & 0.25 & 0.94 & -0.28 \\
\hline DahA & -0.11 & 0.79 & 0.60 & 0.23 & 0.64 & -0.05 & 0.84 & 0.54 & 0.54 & 0.71 & 0.68 & 0.17 \\
\hline BghiP & 0.82 & 0.02 & 0.84 & 0.24 & 0.81 & -0.23 & 0.96 & 0.01 & 0.77 & 0.36 & 0.92 & -0.25 \\
\hline Ind & 0.52 & -0.34 & 0.90 & 0.29 & 0.89 & -0.15 & 0.97 & -0.21 & 0.69 & 0.56 & 0.94 & -0.30 \\
\hline EigenValue & 6.01 & 5.04 & 7.80 & 3.00 & 6.52 & 2.91 & 12.47 & 2.49 & 9.48 & 2.90 & 7.16 & 5.67 \\
\hline Variance $(\%)$ & 37.55 & 31.48 & 48.73 & 18.74 & 40.75 & 18.20 & 77.94 & 15.58 & 59.27 & 18.11 & 44.75 & 35.45 \\
\hline Cumulative $(\%)$ & 37.55 & 69.03 & 48.73 & 67.47 & 40.75 & 58.95 & 77.94 & 93.52 & 59.27 & 77.38 & 44.75 & 80.19 \\
\hline Origin & Vehicular & $\begin{array}{l}\text { Stationary/ } \\
\text { Gasoline }\end{array}$ & Vehicular & $\begin{array}{l}\text { Stationary/ } \\
\text { gasoline }\end{array}$ & Vehicular & $?$ & $\begin{array}{c}\text { Coke/ } \\
\text { Vehicular }\end{array}$ & Oil burning & $\begin{array}{c}\text { Coke/ } \\
\text { Vehicular }\end{array}$ & Stationary & $\begin{array}{c}\text { Coke/ } \\
\text { Vehicular }\end{array}$ & Wood \\
\hline
\end{tabular}

